Volume 15 Issue 1 Year: 2018

\title{
The correlation between right hand finger ratio (2D:4D) and the parameters of anthropometric and physical fitness in children
}

\author{
Nebahat Eler ${ }^{1}$
}

\begin{abstract}
It is hypothesized that there is a correlation between the ratio of second hand finger to fourth hand finger (2D:4D) which is an indicator of prenatal testosterone and physical fitness and sportive performance The aim of this study was to determined correlation between the right hand finger ratio (2D:4D) and the parameters of anthropometric and physical fitness in male and female children aged between 10 and 12. Six hundred and seventy eight males whose age average was $0.49 \pm 1.32$ and 592 females whose age average was $10.38 \pm 1.48$ participated in this study. In addition to taking the students' right hand 2D:4D, height, weight, triceps, subscapular, full arm and leg measurements, vertical jumping, standing long jump, flexibility, $20 \mathrm{~m}$ sprint, 10x5 agility, leg strength, right/left hand grip strength, $20 \mathrm{~m}$ shuttle run and balance tests were also performed. Statistically differences were found between anthropometric measurements apart from height and BMI, 2D:4D and physical fitness parameters in the males and females. A negative correlation between right hand 2D:4D and vertical jumping, standing long jump, $20 \mathrm{~m}$ sprint, 10x5 agility and right hand grip strength in the males. As for the females, although a negative correlation was detected between right hand 2D:4D and height, a positive correlation was found between the same variable and body fat ratio $(p<0.05)$. It can be concluded that while a low 2D:4D ratio was correlated with static and explosive strength, speed and agility in the males, it was correlated with height and body fat ratio in the females.
\end{abstract}

Keywords: 2D:4D; anthropometric measurement; physical fitness; children.

\section{Introduction}

That the testosterone and estrogen concentrations in the womb are at different levels affects the ratio of finger lengths in relation to each other in the children to be born (Manning et al., 1998; Wang, 2016; Kociuba et al., 2017; Ja Chau et al., 2015). As a sign of how much testosterone a human being was exposed to in the uterus, 2D:4D finger length ratios have been accepted (Powel, 2012; Ja Chao and Kim, 2015). Although 2D:4D is the same in males and females until the age of 2 , it shows a difference after that age and it does not change neither in the puberty nor in the adulthood (Manning, 1998). However, according to a study carried out by Ja Cho et al., 2D:4D is the same in the males and females until the age of 4 (2015).

\footnotetext{
${ }^{1}$ Ph.D., School of Physical Education and Sports, Bülent Ecevit University, Zonguldak, nebahateler@gmail.com
} 
Eler, N. (2018). The correlation between right hand finger ratio (2D:4D) and the parameters of anthropometric and physical fitness in children. Journal of Human Sciences, 15(1), 656-664. doi:10.14687/ihs.v15i1.5268

Besides being effective on many areas such as a person's psychological condition (Manning, 2008; Manning et al., 2011; Acar and Eler, 2018), risk of developing cancer or having a heart attack (Manning, 2008; Fink, et al., 2006), sexual preference, mathematical and verbal intelligence, finger ratio is also an indicator of a person's predisposition for sports (Tester and Campell, 2007). Low 2D:4D is accepted to be related to high performance in many sports and 2D:4D has been suggested to have a negative correlation with physical performance in many studies (Manning and Taylor, 2001; Manning, 2002; Paul et al., 2006; Bennett et al., 2010; Hill et al., 2012). Athletes may display differences in competing, seeking excitement and taking risks with respect to their gender. These features are associated with prenatal testosterone exposure as well (Kociuba et al., 2017).

Males have a lower 2D:4D ratio when compared to females (Kociuba et al., 2017; van Honka et al., 2011; Hönekopp and Watson, 2011) and the males who have low 2D:4D ratios tend to have high fertility, reproduction success, aggressiveness and sportive talent ( Wang et al., 2016; Ronald et al., 2002).

The right side is stronger than the left side in terms of all the correlations between 2D:4D and fetal sex steroids. Males tend to use the right side of their body to perform the strongest movements and behaviors (Tanner, 1990; Fink et al., 2006).

There is an increase in the research on the determination of children's physical features. Main reasons for these researches were to investigate the roots of increasing health problems that later arise in the adulthood, to identify children's physical fitness level and sports aptitude to guide them to choose the right sports branch for themselves. In order the identification of 2D:4D finger ratio to be a criterion in talent auditions, more research should be conducted on children and 2D:4D. Most of the studies regarding 2D:4D include adults (Beaton et al., 2011; Fink et al., 2006; Paul et al., 2006; Zhao et al., 2012), adolescents (Peeters et al., 2013), only a single physical fitness parameter (Manning et al., 2000; Manning and Hill, 2009; Folland et al., 2012) and groups of athletes in a single branch of sports (Bilgiç, 2016; Voracek et al., 2010; Kilduff et al., 2011; Tamiya et al., 2012; Manning, 2002; Manning, 2009; Bennet et al., 2010; Sudhakar et al., 2013; Kociuba et al., 2017). The aim of this study is to determined correlation between the right hand finger ratio (2D:4D) and the parameters of anthropometric and physical fitness in male and female children aged $10-12$.

\section{Method}

This study was conducted including the voluntary participation of a total of 1270 primary school students (592 female, 678 male) aged $10-12$. By providing the students' parents and the school administration with detailed information about the study, their consents were obtained. The students did some stretching exercises for 10 minutes before physical fitness tests. Except for $20 \mathrm{~m}$ shuttle run, each test was carried out twice and the best value was recorded.

\section{Anthropometric Measurements}

A Holtain brand anthropometric set was used for the measurements. The weights of the athletes were determined using a digital bascule with a $0.1 \mathrm{~kg}$ of sensitivity and their heights were measured with a stadiometer with a $0.01 \mathrm{~m}$ of sensitivity and the BMI was calculated using the body mess $(\mathrm{kg}) /$ height $(\mathrm{m} 2)$ formula. While the distance between acromion and dactylion was taken into consideration in the determination of arms Length (AL), the distance between the tibial condyle and medial malleolus was taken into account when measuring Leg Length (LL) and the obtained data was recorded with a sensibility of $1 / 10 \mathrm{~cm}$. A skinfold caliper was used for the measurement of Body Fat Ratio (BFR). Besides, triceps and subscapular skin measurements were performed and calculated (Lohman, 1992). After the students' photocopy images of their right hands were taken, their finger lengths were measured using a vermian caliper that can measure up to $0.05 \mathrm{~mm}$ between the basal line at the proximal part of the $2^{\text {nd }}$ finger (index finger) and the $4^{\text {th }}$ finger (ring finger) on the palm of their right hands. The measurements were carried out by the same person twice to ensure reliability and they were noted down in millimeters $(\mathrm{mm})$. In 
Eler, N. (2018). The correlation between right hand finger ratio (2D:4D) and the parameters of anthropometric and physical fitness in children. Journal of Human Sciences, 15(1), 656-664. doi:10.14687/jhs.v15i1.5268

addition, to determine the ratio, the length of the second finger was divided into the length of the fourth finger.

\section{Physical Fitness Measurements}

The explosive strength Vertical Jumping (VJ) and Standing Broad Jump (SBJ) tests were recorded in centimeters $(\mathrm{cm})$. After marking the highest point on the wall that the subject can reach while standing, the highest point $\mathrm{s} /$ he can touch by jumping in a position that their feet touch each other by getting strength from the knees (by bending them) was also marked and the difference between the two points were recorded. In the SBJ test, the subject jumped forward on two feet from the start line and the farthest distance that $\mathrm{s} /$ he jumped was recorded as the test result. The speed was measured by $20 \mathrm{~m}$ Sprint Test in seconds (sec) and the participants sprinted from the start line for 20 meters after getting the start signal.

The elapsed time between the start and finish line was detected by a photocell (New Test 2000) and the speed and agility tests were performed by 10x5 m agility test (sec). A rectangular run-up area which was $1.2 \mathrm{~m}$ wide and $5 \mathrm{~m}$ long was formed for this test which means running at the end of the track and returning at the maximum speed and then the total time was recorded. To determine the static strength, Leg Strength (LS) (kg), Right Hand Grip Strength (RHGS) and Left Hand Grip Strength (LHGS) tests $(\mathrm{kg})$ were performed. The LS test was carried out using a Takkei back and lift dynamometer. After the subjects placed their feet on the dynamometer stand in a knee bent case, while the arms were stretched, the back was flat and the torso was slightly bent forward, they grasped the bar of the dynamometer by their hands and lift it up vertically at their maximum using their legs. Then the value was recorded. A hand dynamometer which was adjusted based on the hand measurement of the subject was utilized for RHGS and LHGS and by applying the grip strength without bending the arm from the elbow, the measurement was taken. To determine the endurance, $20 \mathrm{~m}$. Shuttle Run (endurance) test was performed on a once a day basis on a different day. The obtained scores were used to find out the subjects' maximal oxygen uptake and the values were calculated in $\mathrm{ml} / \mathrm{kg} / \mathrm{min}$ by using an evaluation table. So as measure the flexibility, the Sit and Reach (SR) test was conducted. While on sitting position, the subject stretched forward with both hands as far as possible holding this position for 1 or 2 seconds and the distance was recorded. Finally, the Flamingo balance test was performed to measure balance. The participant tried to stand on a balance board on the dominant foot with his/her shoe on for a minute and the number of trials was determined.

\section{Statistical Analysis}

The Kolmogorov-Smirnov test was used for normality of data. In the analysis of normally distributed data, independent samples t-test was used for comparison of two groups, and pearson correlation analysis was used to determine the relationship between variables. Significance was set at $\mathrm{p}<0,05$." 
Eler, N. (2018). The correlation between right hand finger ratio (2D:4D) and the parameters of anthropometric and physical fitness in children. Journal of Human Sciences, 15(1), 656-664. doi:10.14687/jhs.v15i1.5268

\section{Results}

Table 1. The correlation between anthropometric and physical fitness parameters between the male and female students

\begin{tabular}{|c|c|c|c|c|c|}
\hline \multirow{3}{*}{ Değişkenler } & & ( male; $\mathrm{n}-678$ ) & ( female; n-592) & & \\
\hline & Variables & Mean \pm Std. Deviation & Mean \pm Std. Deviation & $\mathrm{t}$ & $\mathrm{p}$ \\
\hline & Age (year) & $10.49 \pm 1.32$ & $10.38 \pm 1.48$ & 1.399 & 0.16 \\
\hline \multirow{7}{*}{$\begin{array}{l}\text { Anthropometric } \\
\text { Measurements }\end{array}$} & Height $(\mathrm{cm})$ & $140.67 \pm 9.43$ & $141.43 \pm 8.16$ & -1.524 & 0.12 \\
\hline & Weight $(\mathrm{kg})$ & $36.66 \pm 9.43$ & $37.84 \pm 8.63$ & -2.313 & $0.02 *$ \\
\hline & BMI $(\mathrm{kg} / \mathrm{m} 2)$ & $21.70 \pm 6.23$ & $22.42 \pm 7.35$ & -1.889 & 0.05 \\
\hline & Body Fat Ratio (\%) & $25.06 \pm 8.70$ & $27.16 \pm 8.95$ & -4.225 & $0.00^{*}$ \\
\hline & Leg Length $(\mathrm{cm})$ & $62.81 \pm 7.45$ & $64.08 \pm 6.99$ & -3.373 & $0.03^{*}$ \\
\hline & Arm Length $(\mathrm{cm})$ & $56.78 \pm 8.21$ & $57.81 \pm 9.12$ & -2.102 & $0.03^{*}$ \\
\hline & Right Hand 2D:4D & $0.941 \pm 0.039$ & $0.967 \pm 0.029$ & -13.583 & $0.00^{*}$ \\
\hline \multirow{10}{*}{$\begin{array}{c}\text { Physical Fitness } \\
\text { Parameters }\end{array}$} & Vertical Jumping (cm) & $17.09 \pm 5.61$ & $15.45 \pm 4.94$ & 5.539 & $0.000^{*}$ \\
\hline & Standing Long Jump (cm) & $128.53 \pm 20.68$ & $117.43 \pm 16.48$ & 10.634 & $0.000 *$ \\
\hline & Flexibility $(\mathrm{cm})$ & $18.57 \pm 6.07$ & $23.73 \pm 7.61$ & -13.227 & $0.000 *$ \\
\hline & $20 \mathrm{~m}$ Sprint (sec) & $4.61 \pm 0.57$ & $4.89 \pm 0.89$ & -6.568 & $0.000 *$ \\
\hline & $10 \times 5 \mathrm{~m}(\mathrm{sec})$ & $24.97 \pm 2.79$ & $29.48 \pm 3.41$ & -25.564 & $0.000^{*}$ \\
\hline & Leg Strength $(\mathrm{kg})$ & $39.37 \pm 12.33$ & $30.14 \pm 10.52$ & 14.394 & $0.000 *$ \\
\hline & Right Hand Grip Strength (kg) & $16.64 \pm 4.41$ & $15.19 \pm 5.78$ & 4.970 & $0.000 *$ \\
\hline & Left Hand Grip Strength (kg) & $14.40 \pm 4.08$ & $13.42 \pm 6.42$ & 3.226 & $0.000^{*}$ \\
\hline & $\mathrm{MaxVO}_{2}(\mathrm{ml} . \mathrm{kg} / \mathrm{min})$ & $31.8 \pm 3.41$ & $31.3 \pm 2.24$ & 3.123 & $0.001 *$ \\
\hline & Balance & $9.7 \pm 5.25$ & $10.8 \pm 7.46$ & -2.997 & $0.002 *$ \\
\hline
\end{tabular}

$\mathrm{p}<0.05$

Considering the results of the anthropometric measurement, the mean values of weight, BFR, arm/leg length and right hand 2D:4D were higher in the females than those of the males. As for the results of the physical fitness parameters, all the mean values of these parameters were higher in the males than those of the females, except for flexibility and a significant meaningful difference was found statistically among each other $(p<0.05)$. When the overall picture was taken into account, there was a meaningful difference in all the parameters between the males and females apart from age, height, and BMI.

Table 2. The correlation between right hand 2D:4D and anthropometric features of the male and female students

\begin{tabular}{|c|c|c|c|}
\hline \multirow{2}{*}{ Değişkenler } & & Males & Females \\
\hline & & Right hand 2D:4D & Left hand 2D:4D \\
\hline \multirow{2}{*}{ Age (year) } & $\mathrm{r}$ & 0,23 & 0,18 \\
\hline & $\mathrm{p}$ & 0,16 & 0,33 \\
\hline \multirow{2}{*}{ Height (cm) } & $\mathrm{r}$ & 0,22 & $-0,17$ \\
\hline & $\mathrm{p}$ & 0,14 & $0.04 *$ \\
\hline \multirow{2}{*}{ Weight (kg) } & $\mathrm{r}$ & $-0,04$ & $-0,04$ \\
\hline & $\mathrm{p}$ & 0,17 & 0,27 \\
\hline \multirow{2}{*}{ BMI (kg/m2) } & $\mathrm{r}$ & $-0,12$ & 0,11 \\
\hline & $\mathrm{p}$ & 0,41 & 0,06 \\
\hline \multirow{2}{*}{ Body Fat Rate (\%) } & $\mathrm{r}$ & 0,07 & 0,57 \\
\hline & $\mathrm{p}$ & 0,14 & $0.00^{*}$ \\
\hline \multirow{2}{*}{ Leg Length $(\mathrm{cm})$} & $\mathrm{r}$ & 0,03 & 0,14 \\
\hline & $\mathrm{p}$ & 0,25 & $-0,01$ \\
\hline \multirow{2}{*}{ Arm Length $(\mathrm{cm})$} & $\mathrm{r}$ & 0,06 & $-0,33$ \\
\hline & $\mathrm{p}$ & 0,14 & 0,29 \\
\hline
\end{tabular}

$\mathrm{p}<0.05$ 
Eler, N. (2018). The correlation between right hand finger ratio (2D:4D) and the parameters of anthropometric and physical fitness in children. Journal of Human Sciences, 15(1), 656-664. doi:10.14687/jhs.v15i1.5268

In the females, a weak negative correlation between right hand 2D:4D and height and LL were detected, whereas there was a moderate positive correlation between the same variable and BFR. As for the males, no correlation was detected between right hand 2D:4D and anthropometric measures.

Table 3. The correlation between right hand 2D:4D and physical fitness parameters in the males and females

\begin{tabular}{|c|c|c|c|}
\hline \multirow{2}{*}{ Değişkenler } & & Males & Females \\
\hline & & Right hand 2D:4D & Left hand 2D:4D \\
\hline \multirow{2}{*}{ Vertical Jump (cm) } & $\mathrm{r}$ & $-0,25$ & $-0,05$ \\
\hline & $\mathrm{p}$ & $0.06^{*}$ & 0,06 \\
\hline \multirow{2}{*}{ Standing Broad Jump ( $\mathrm{cm})$} & $\mathrm{r}$ & $-0,01$ & $-0,01$ \\
\hline & $\mathrm{p}$ & $0.17 *$ & 0,21 \\
\hline \multirow{2}{*}{ Sit and Reach $(\mathrm{cm})$} & $\mathrm{r}$ & $-0,01$ & $-0,06$ \\
\hline & $\mathrm{p}$ & 0,12 & 0,33 \\
\hline \multirow{2}{*}{$20 \mathrm{~m}$ sprint (sec) } & $\mathrm{r}$ & $-0,11$ & $-0,06$ \\
\hline & $\mathrm{p}$ & $0.04 *$ & 0,07 \\
\hline \multirow{2}{*}{$10 \times 5 \mathrm{~m}(\mathrm{sec})$} & $\mathrm{r}$ & $-0,21$ & 0,03 \\
\hline & $\mathrm{p}$ & $0.01 *$ & 0,16 \\
\hline \multirow{2}{*}{ Leg Strength(kg) } & $\mathrm{r}$ & $-0,07$ & $-0,12$ \\
\hline & $\mathrm{p}$ & 0,06 & 0,21 \\
\hline \multirow{2}{*}{$\begin{array}{l}\text { Hand Grip Strength (right) } \\
\text { (kg) }\end{array}$} & $\mathrm{r}$ & $-0,31$ & $-0,01$ \\
\hline & $\mathrm{p}$ & $0.02 *$ & 0,08 \\
\hline \multirow{2}{*}{$\begin{array}{l}\text { Hand Grip Strength (left) } \\
(\mathrm{kg})\end{array}$} & $\mathrm{r}$ & 0,06 & $-0,04$ \\
\hline & $\mathrm{p}$ & 0,23 & 0,19 \\
\hline \multirow{2}{*}{$\mathrm{MaxVO}_{2}(\mathrm{ml} . \mathrm{kg} / \mathrm{min})$} & $\mathrm{r}$ & 0,01 & $-0,05$ \\
\hline & $\mathrm{p}$ & 0,31 & 0,21 \\
\hline \multirow{2}{*}{ Balance } & $\mathrm{r}$ & 0,11 & 0,12 \\
\hline & $\mathrm{p}$ & 0,21 & 0,38 \\
\hline
\end{tabular}

Considering the performance parameters, although there was a negative correlation between right hand 2D:4D and VJ, SBJ, $20 \mathrm{~m}$ sprint, $10 \times 5$ agility and right hand grip strength, no correlation could be found between right hand $2 \mathrm{D}: 4 \mathrm{D}$ and these parameters in the females.

\section{Conclusion and Discussion}

Although there are a good number of studies regarding 2D:4D in the literature, there are only a few studies concerning the correlation between 2D:4D ratio and physical fitness parameters in children and adolescents (Eghbali, 2016; Bilgiç et al., 2016; Ranson et al., 2015; Wang et al., 2016). Besides, it is a handicap that the results of all these studies are different from each other and it is assumed that the differences stem from the number of the subjects, their age, and frequency of doing physical exercise.

Folland et al., (2012) in young males, Peeters et al., (2013) in young females, Mehdizadeh et al., (2013) in female university students (n-40), Eghbali (2016) in male children aged 7-13 (n316), Bilgiç et al., (2016) in children aged 11-13 who are engaged in different sports branches (f37, m-57), Bilgiç et al., (2016) in 39 females and 57 males aged 11-13 in different sports branches, and in a similar study Eghbali (2016) in male students aged 7-13 examined the correlation between 2D:4D ratio and physical fitness and observed no significant correlation between 2D:4D ratio and strength, endurance, speed, agility and flexibility. Contrary to these results, Wang et al., (2016) reported a strong negative correlation between 2D:4D and fine and gross motor skills in a study conducted on 40 male and 40 female children in the same age group. Ranson et al., (2015) investigated the correlation between 2D:4D and physical fitness in a study in which 922 male and 835 female students participated and stated a negative correlation between 2D:4D and strength, endurance and speed in the males. 
Eler, N. (2018). The correlation between right hand finger ratio (2D:4D) and the parameters of anthropometric and physical fitness in children. Journal of Human Sciences, 15(1), 656-664. doi:10.14687/jhs.v15i1.5268

On the other hand, Fink et al., (2003) identified a positive correlation between 2D:4D and BMI- waist and hip circumference- in adult males ( $n-50)$ and females (n-70), while Müller et al., (2013) did not find a significant correlation between 2D:4D and some anthropometric measurements such as BMI and waist in adults (n-14,916). This contradiction might stem from the number of participants who were involved in the studies. Although Ranson et al., (2015) reported a significant correlation between 2D:4D and height, weight, BMI, and waist circumference in the females, they did not observe any correlation in the males. In our study; however, while there was a weak negative correlation between 2D:4D and height $(r=-0.17)$, and a moderate positive correlation between 2D:4D and BFR $(r=0.57)$ in the females, no correlation was found in the males.

In the study they carried out on young males, Manning and Hill (2009) indicated a negative correlation between right/left hand 2D:4D and $20 \mathrm{~m}, 30 \mathrm{~m}, 40 \mathrm{~m}$ and $50 \mathrm{~m}$ sprint speed. Ranson et al., (2015) found a significant and negative correlation in the males aged 8-12 between 2D:4D and $5 \times 10 \mathrm{~m}$ sprint, which is consistent with our results. Though it was weak, there was a negative correlation between $2 \mathrm{D}: 4 \mathrm{D}$ and speed $(\mathrm{r}=-0.11)$ and agility $(\mathrm{r}=-0.21)$.

Zhao et al., (2015) suggested that there was a strong correlation between the cardiovascular system and muscle strength due to prenatal testosterone in the males but reported no evidence for the females. In studies examining the correlation between 2D:4D and strength, Grip Strength (GS) test which determines the static strength is utilized (Ranson et al., 2015; Bilgiç et al., 2016; Eghbali, 2016; van Anders, 2007; Gallup et al., 2007; Zhao et al., 2012).

In our study, while there was a moderate negative correlation between 2D:4D and GS in the males, no relationship was found in the females. Fink et al., (2006) and Zhao et al., (2012) suggested that there was a negative correlation between 2D:4D and GS, whereas Zhao et al., (2012) and Hone and McCullough (2013) confirmed that there was not a correlation in the females for the same variable. Furthermore, there are many studies proving that there is no correlation between 2D:4D and static strength (van Anders, 2007; Gallup et al., 2007, Halil and Gürel, 2012).

In the present study, no correlation between 2D:4D and endurance was found in the male and female children. In their studies, Manning et al., 2007 and Fink et al., 2003 determined that the strongest correlation was between 2D:4D and endurance parameters when compared to speed and strength in adults (f-50, m-30). On the other hand, Ranson et al., (2015) reported a strong relationship between 2D:4D and endurance in a study conducted on 922 male and 835 female students.

There is also some research indicating that there is a strong correlation between $2 \mathrm{D}: 4 \mathrm{D}$ and sportive performance in the males who are middle and long distance runners (Manning et al., 2008; Manning et al., 2007; Manning et al., 2009).

Peeters et al., (2013) in young females (n-178), Hill et al., (2012) in young males (n-41), Eghbali, (2016) in male children ( $\mathrm{n}-316)$ detected a significant correlation between right/left 2D:4D and maximal oxygen intake.

While Ranson et al., (2015) suggested that the level of prenatal testosterone and estrogen had effects on speed, endurance and strength on male children in a study conducted on children, Hönekopp et al., (2006) reported a significant correlation between left hand 2D:4D $(r=20.32)$ and physical fitness parameters in a study involving young females, but this relationship was not observed for right hand.

As a result of the study conducted on young females aged 13.5-18, Peeters et al., (2013) claimed that there was no correlation between left hand 2D:4D ratio and any physical fitness components (balance, limb movement speed, flexibility, explosive strength, static strength, body strength, functional power, speed/ agility and endurance) and anthropometric variables (height, weight, BMI and somatotype components). Therefore, they stated that 2D:4D should not be among the criteria for females in talent auditions. 
Eler, N. (2018). The correlation between right hand finger ratio (2D:4D) and the parameters of anthropometric and physical fitness in children. Journal of Human Sciences, 15(1), 656-664. doi:10.14687/jhs.v15i1.5268

In a study carried out by Manning and Taylor (2001), it was indicated that the males who have low 2D:4D ratios are more successful in many sports and have better balance and coordination skills, which is a positive feature in sports. However, contrary to this result, no relationship was found in our study between 2D:4D and balance in males and females.

Although the results of the studies that have been conducted so far to examine the relationship between 2D:4D and sports, performance and physical fitness have presented differences, it is thought that these differences are due to the number of participants, their age and frequency of doing physical exercise.

In the present study, it was revealed that the ratio of the male students' $2 \mathrm{D}: 4 \mathrm{D}$ was lower than that of the females. Besides, as a result of this research, a significant difference was found between 2D:4D and anthropometric and physical fitness parameters, except for age, height and BMI in the male and female students aged 10-12. While there was a negative correlation between right hand 2D:4D and static strength (RHGS), explosive strength (VJ, SLJ), speed and agility (20 $\mathrm{m}$ sprint and $10 \times 5 \mathrm{~m}$ ), a negative relationship with height and a positive relationship with BFR were determined in the females. To conclude, while $2 \mathrm{D}: 4 \mathrm{D}$, which is an indicator of fetal testosterone, can be a reference point for male children in talent auditions for the sports branches requiring strength and speed as well as in guiding them to the right sport, it should not be a criterion for performance in females. If this study is conducted on the children engaging in sports or larger populations, different results might be obtained.

\section{References}

Acar, H., Eler, N. (2018). The Relationship of Digit Ratio (2D:4D) with Cerebral Lateralization and Grip Strength in Elite Swimmers. Journal of Education and Training Studies, 6(4), 84-89., Doi: 10.11114/jets.v6i4.3040.

Beaton, A.A., Rudling, N., Kissling, C., Taurines, R.\& Thome, J. (2011). Digit ratio (2D:4D), salivary testosterone, and handedness. Laterality: Asymmetries of Body, Brain and Cognition, 16(2), 136-155. 10.1080/13576500903410369[doi].

Bennett, M., Manning, J.T., Cook, C.J., Kilduff, L.P. (2010). Digit ratio (2D: 4D) and performance in elite rugby players. Journal of Sports Sciences, 28(13), 1415-1421. 928660707[pii];10.1080/02640414.2010.510143 [doi].

Bilgiç, M., Biçer, M., Özdal, M. (2016). Farklı Branşlarda Spor Yapan 11-13 Yaş Grubu Çocukların 2D:4D Parmak Oranlarının Sportif Performansla İlişkisinin İncelenmesi. Gaziantep Üniversitesi Beden Eğitimi ve Spor Bilimleri Dergisi, 1(1), 48-56.

Eghbali, E. (2012). The relationship between digit ratio (2D:4D) and physical fitness in boys 7 to 13 years. Physical Activity Review, 4, 154-162. 10.16926/par.2016.04.19[doi].

Fink, B., Neave, N., Manning, J.T. (2003). Second to fourth digit ratio, body mass index, waist-tohip ratio, and waist-to-chest ratio: their relationships in heterosexual men and women. Ananals of Human Biology, 30(6), 728-738. 10.1080/03014460310001620153[doi].

Fink, B., Thanzami, V., Seydel, H., Manning, JT. (2006). Digit ratio and hand-grip strength in German and Mizos men: Cross-cultural evidence for an organizing effect of prenatal testosterone on strength. American Journal of Human Biology, 18(6), 776-782. 10.1002/ajhb.20549 [doi].

Folland, J.P., Mc Cauley, T.M., Phypers, C., Hanson, B., Mastana, S.S.. (2012). Relationship of 2D:4D finger ratio with muscle strength, testosterone, and androgen receptor CAG repeat genotype. American Journal of Physical Anthropology, 148(1), 81-77. 10.1002/ajpa.22044[doi].

Gallup, A.C., White, D.D., Gallup, G.G. (2007). Handgrip strength predicts sexual behavior, body morphology, and aggression in male college students. Evolution and Human Behavior, 28:, 423-429. 
Eler, N. (2018). The correlation between right hand finger ratio (2D:4D) and the parameters of anthropometric and physical fitness in children. Journal of Human Sciences, 15(1), 656-664. doi:10.14687/jhs.v15i1.5268

Halil, M, Gürel, E.I., Kuyumcu, M.E., Karaismailoglu, S., Yesil, Y., et al. (2012). Digit (2D:4D) ratio is associated with muscle mass (MM) and strength (MS) in older adults: Possible effect of in utero androgen exposure. Archives of Gerontol Geriatrics, 56(2), 358-363. 10.1016/j.archger.2012.11.003 [doi].

Hill, R., Simpson, B., Manning, J., Kilduff, L. (2012). Right-left digit ratio (2D:4D) and maximal oxygen uptake. Journal of Sports Science, 30, 129-134. 10.1080/02640414.2011.637947 [doi].

Hone, L.S.E., Mc Cullough, M.E., 2012. 2D:4D ratios predict hand grip strength (but not hand grip endurance) in men (but not women). Evolution and Human Behavior, 33, 780-789. https://doi.org/10.1016/j.evolhumbehav.2012.07.003.

Hönekopp, J., Manning, T., Muller, C. (2006). Digit ratio (2D:4D) and physical fitness in males and females: Evidence for effects of prenatal androgens on sexually selected traits). Evolution and Human Behavior, 49, 545-549. 10.1016/j.yhbeh.2005.11.006 [doi].

Hönekopp, J., \& Watson, S. (2011). Meta-analysis of the relationship between digit-ratio 2d:4d and aggression. Personality and Individual Differences, 51, 381-386. 10.1002/ajhb.21054 [doi].

Ja Cho, K. and Kim, S. (2015). Change of Second to Fourth Digit Ratio according to Age in Korean Children. Korean Journal of Physical Anthropology, 28(4), 197-203. 10.11637/kjpa.2015.28.4.197[doi].

Kilduff, L.P., Cook, C.J., Manning, J.T. (2011). Digit ratio (2D:4D) and performance in male surfers. The Journal of Strength \& Conditioning Research, 25(11), 3175-3180. 10.1519/JSC.0b013e318212de8e[doi].

Kociuba, M., Koziel, S., Chakraborty, R., Ignasiak, Z. (2017). Humans exhibit sex differences in competitiveness, sensation seeking and risk-taking attitude, which are required in sports. Journal of Biosocial Science, 49(5), 623-633.

Lohman, T.G. (1992). Advances in body composition assessment. Champaign, Ill: Human Kinetics.

Manning, J.T, Scutt D, Wilson J, Lewis-Jones D.I. (1998). The Ration of 2. To 4. Digit Length: a prediditor of sperm numbers and concentrations of testosterone, luteinizing hormone and oestrogen. Human Repord, 13(11), 3000-3004. 10.1093/humrep/13.11.3000[doi].

Manning, J.T., Barley, L.,Walton, J., Lewis-Jones, D.I., Trivers, R.L., Singh, D., et al. (2000). The 2nd:4th digit ratio, sexual dimorphism, population differences and reproductive success: evidence for sexually antagonistic genes. Evolution and Human Behavior, 21, 163-83. 10.1016/S1090-5138(00)00029-5[doi].

Manning, J.T. and Taylor R.P. (2001). Second to fourth digit ratio and male ability in sport: implications for sexual selection in humans. Evolution and Human Behavior, 22(1): 61 69. 10.1016/S1090-5138(00)00063-5[doi].

Manning, J.T. (2002). The ratio of the 2nd to 4th digit length and performance in skiing. Journal of Sports Medicine Physical Fitness, 42, 446-50.

Manning, J.T., Morris, L., Caswell, N. (2007). Endurance running and digit ratio (2D:4D): implications for fetal testosterone effects on running speed and vascular health. American Journal of Human Biology, 19, 416-421. 10.1002/ajhb.20603 [doi].

Manning, J.T., Fink, B. (2008). Digit ratio (2D:4D), dominance, reproductive success, asymmetry, and sociosexuality in the BBC Internet Study. American Journal of Human Biology, 20(4), 451-461. 10.1002/ajhb.20767[doi].

Manning, J.T. and Hill, M.R. (2009). Digit ratio (2D:4D) and sprinting speed in boys. American Journal of Human Biology, 21(2), 210-213. 10.1002/ajhb.20855[doi].

Manning, J.T. (2011). Resolving the role of prenatal sex steroids in the development of digit ratio. PNAS, 108(39), 16143-16144. 10.1073/pnas.1113312108[doi]. 
Eler, N. (2018). The correlation between right hand finger ratio (2D:4D) and the parameters of anthropometric and physical fitness in children. Journal of Human Sciences, 15(1), 656-664. doi:10.14687/jhs.v15i1.5268

Mehdizadeh, R., Sarhozaki, N., Abbasi, S. (2013). Relationship between second to fourth digit ratio (2D: 4D) and dynamic muscular endurance in trained girl students. International Journal of Sport Studies, 3(1), 99-104.

Muller, D.C., Manning, J.T., Hopper, J.L., English, D.R., Giles, G.G., Severi, G. (2013). No strong association between second to fourth digit ratio (2D:4D) and adult anthropometric measures with emphasis on adiposity. Ananals of Human Biology, 40(2), 201-204. 10.3109/03014460.2012.751127[doi].

Paul, S.N., Kato, B.S., Hunkin, J.L., Vivekanandan, S., Spector, T.D. (2006). The big finger: the second to fourth digit ratio is a predictor of sporting ability in women. British Journal of Sports Medicine, 40, 981-983. 10.1136/bjsm.2006.027193 [doi].

Peeters, M.W., Van Aken, K., Claessens, A.L. (2013). The left hand second to fourth digit ratio (2D:4D) is not related to any physical fitness component in adolescent girls. PLoS One, 8(4), e59766. 10.1371/journal.pone.0059766[doi].

Phelps VR., (1952). Relative index finger length as a sex influenced trait in man. American Journal of Human Genetics, 4:472-89.

Powel, JL, Parkes, L, Kemp, GJ et al. (2012). The effect of sex and handedness on white matter anisotropy: a diffusion tensor magnetic resonance imaging study. Neuroscience, 59, 227 242. 10.1016/j.neuroscience.2012.01.016[doi].

Ranson, R., Strattonb, G., Taylor, S.R. (2015). Digit ratio (2D:4D) and physical fitness (Eurofit test battery) in school children. Early Human Development, 91, 327-331. 10.1016/j.earlhumdev.2015.03.005[doi].

Ronald, G., Phillips, D.I.W., Godfrey , K.M., Manning, J.T. (2002). The ratio of second to fourth digit lengths: a marker of impaired fetal growth? Early Human Development, 68(1), 21 26. 10.1016/S0378-3782(02)00009-9[doi].

Sudhakar, H.H., Veena, U.B., Tejaswi ,R.N. (2013). Digit ratio (2D:4D) and performance in Indian swimmers. Indian Journal of Physiology Pharmacology, 57(1), 72-6.

Tamiya, R., Lee, S.Y. Ohtake, F., 2012. Second To Fourth Digit Ratio And The Sporting Success Of Sumo Wrestlers. Evolution And Human Behavior, 33: 130-136.

Tanner, J.M., (1990). Foetus into Man: Physical Growth from Conception to Maturity. New York: Harvard Univ Press

Tester, N. and Campbell, A. (2007). Sporting achievement: What is the contribution of digit ratio? Journal of Personality, 75(4), 663-677. 10.1111/j.1467-6494.2007.00452.x [doi].

Van Anders, S.M. (2007). Grip strength and digit ratios are not correlated in women. American Journal of Human Biology., 19(3), 437-439. 10.1111/j.1600-0838.2009.01031.x [doi].

Van Honka, J., Schutter, D.J., Bos, P.A., Kruijt, A.W., Lentjes, E.G. \& Baron-Cohen, S. (2011). Testosterone Administration Impairs Cognitive Empathy İn Women Depending On Second-To-Fourth Digit Ratio. Proceedings Of The National Academy Of Sciences Of The United States Of America, 108, 3448-3452.10.1073/pnas.1011891108[doi].

Voracek, M., Reimer, B., Dressler, S.G. (2010). Digit ratio (2D:4D) predicts sporting success among female fencers independent from physical, experience, and personality factors. Scandinavian Journal of Medicine\&Science in Sports, 20(6), 853-860. 10.1111/j.16000838.2009.01031.x [doi].

Wang, Y, Wang, H.L.,. L1, Y.H., Zhu, F.L., L1, S.J., N1, H. (2016). Using 2D: 4D digit ratios to determine motor skills in children. European Review for Medical and Pharmacological Sciences, 20, 806-809.

Zhao, D., Li, B., Yu, K., Zheng, L. (2012). Digit ratio (2D: 4D) and handgrip strength in subjects of Han ethnicity: impact of sex and age. American Journal of Physical Anthropology, 149(2), 266-271. 10.1002/ajpa.22130 [doi]. 